\title{
INVESTIGATION OF THE STABILITY OF ENGINE - GOVERNOR SYSTEM OPERATED AT LOW SPEEDS
}

\author{
Cuthbert F. Mhilu and Iddi S.N. Mkilaha \\ University of Dar es Salaam, Department of Energy Engineering \\ P.O. Box 35131, Dar es Salaam, Tanzania \\ E-mail: cfmhilu@hotmail.com
}

\begin{abstract}
D uring diesel engine operation, a tendency for the engine not to achieve a steady idling speed has often been observed. During idling speed the engine tends to either race or stall as a result of poor and incorrect metering of the fuel, which is required for the combustion process and if severe, the engine will stop firing completely. In this research an investigation was made to establish knowledge on diesel engine stability operated at low speeds. The influence of a governor of an engine in the control of the engine speeds has also been investigated. In order to obtain information on the engine operation condition, use has been made of a mathematical model that incorporates the engine, governor and a tachometer. A simulation was conducted by solving the system's differential equations using a fourth order Runge-Kutta numerical integration method written in $\mathrm{C}$ code computer programs. The results obtained show the stability of the engine- governor system operated at low speed to be stable. When the engine was subjected to some parameter variations the engine showed some sign of instability occurring at increased disturbance intensities. Based on the obtained results an enhanced knowledge has been obtained giving an indication on how the existing mechanical engine speed governors design features could be improved to achieve engine stability at low speeds.
\end{abstract}

Keywords: $\quad$ Engine, Governor, Stability, Speed, Control

\section{INTRODUCTION}

In diesel engines, a tendency for the engine not to achieve a steady idling speed has widely been observed. There are a number of problems pertaining to such instabilities ranging from combustion phenomenon to engine and auto performance in general [Choi 1998, Shoji 1997 and Chan 1997]. Present level of knowledge explain the problem of the engine to stall being a result of poor and incorrect metering of the fuel. This is required for the combustion process taking place during engine operation. Other problem arises form rough or incorrect engine idling speed tuning and when severe, the engine can stop firing completely [Yamaguchi, 1984].

When a diesel engine is started the control rod which is linked to the injection pump, sets it in such a way that it delivers sufficient fuel to the engine ready to start it. When the engine fires the control rod rectifies the operation of the injection pump and controls the amount of fuel which is required for proper idling speed of the engine. Speed governors in diesel engines play key role in the control of the idling speed as well as maximum speed of an engine achieved by adjusting the amount of fuel supplied to the engine. It has been established that if not properly governed, diesel engines could stall and stop completely. The stalling phenomenon affects the stability of the engine and this effect is severe especially at low speed operation [Yamaguchi, 1984 and Khovakh et al, 1979], due to improper quantity of fuel delivered into the combustion chamber.

Problems in diesel engines failing to achieve a steady idling speed have widely been reported [Balluchi et al, 2002]. Problems of stalling in diesel engines operated at low speeds as a result of incorrect metering of the fuel undermine severely the engine stability [Hillier and Pittuck, 1972] thereby affecting the combustion process.

In this paper an investigation of the influence of speed governor design characteristics on the stability of the engine operated at low speeds is carried out. The study enhance the current level of knowledge on the influence of speed 
governor parameter settings on engine operation stability at low speeds that could be applied for the improvement of mechanical governor designs [Hillier and Pittuck, 1972]. The results obtained from this study add into a better understanding of the influence of a speed governor on the stability of engines operated at low speeds. It has also been shown that through tracing and understanding of engine instabilities, it is possible to re-design and adjust engine and governor parameters so as to improve the thermodynamic cycles of an operating engine [Chan 1997, Santillan et al, 2001].

\section{DERIVATION OF SYSTEM MODELS}

In order to obtain a qualitative understanding of the influence of speed governor parameter settings on the behaviour of an engine operated at low speeds, a mathematical modeling is used to simulate the performance and operation of a diesel engine incorporating a mechanical speed governor. This necessitates the development of mathematical relations relating to the necessary signal transfer and actions to be solved using digital computer to yield the instantaneous responses in terms of fuel rack displacements as input and actual engine speed as output, in accordance to the arrangement of components comprising a physical engine model [Mhilu, 1995]. The appropriate mathematical representations of each or a group of components used have been developed on the basis of the following block diagram.

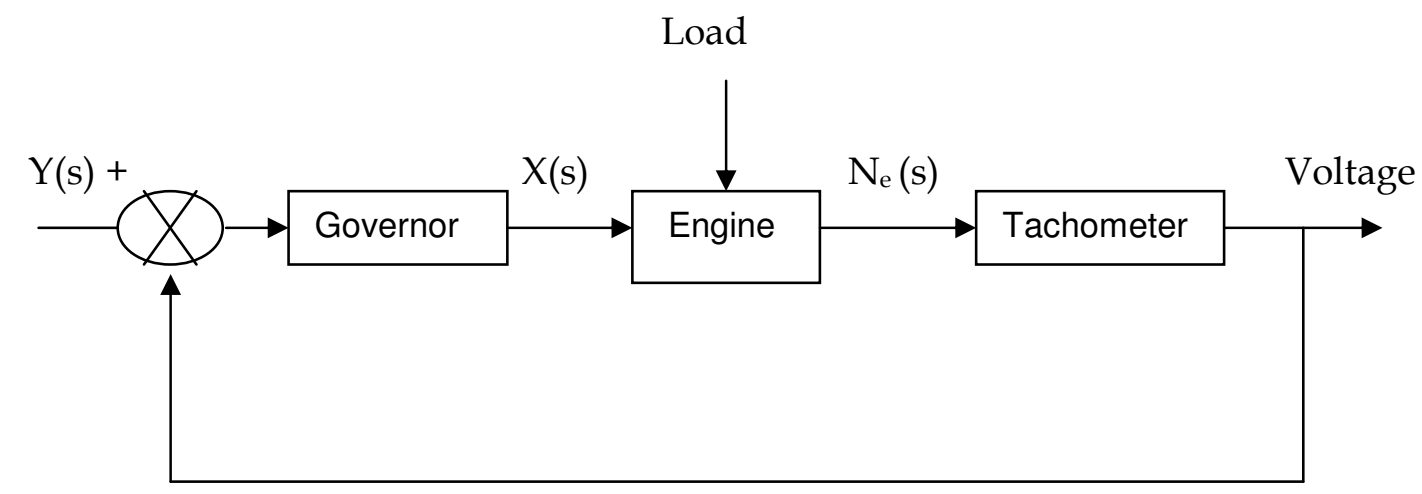

Figure: 1 Block diagram of a speed governing mechanism

\section{Speed governor}

In a diesel engine, the governor controls the speed of the engine by measuring crankshaft speed and reacting to speed variations due to changes in load to maintain proper engine speed by adjusting a rack unit connected to the fuel pump [Susheel et al, 2002]. For the case of mechanical speed governors, when the engine fires, the rotation of weights causes a centrifugal force to overcome spring tension to adjust the amount of fuel injected [Khovakh et al, 1979]. In order to investigate the effects of the speed governor characteristic variations on the engine operational stability, use has been made of the governing equation of a typical mechanical governor represented by a transfer function of the form shown in equation 1 [Schwarzenbach and Gill, 1984].
$G_{1}=\frac{X(s)}{Y(s)}=\frac{1}{s^{2}+b s+d}$

where, $X(s)$ represents the position of the fly weight mass, $Y(s)$ being the fuel rack displacement, and the constants have been evaluated for this study to be $b=c / M=100$, where $M=$ is the mass of fly weight $(\mathrm{kg}), c=$ is the damping coefficient, and $d=k / M=1200$, where $k=$ is the spring stiffness of the governor system [Bosch, 1986 and Heisler, 1985].

\section{The Engine}

The performance of an internal combustion engine is determined by its load and speed, which may change within a definite range. The factors that are decisive of the upper speed limit in diesel engines are the quality of the process, thermal stresses of the engine 
elements, reduced mechanical efficiency and the increased inertia loads and wear of engine units. The idle speed control problem deals with the task of maintaining the stability of engine operating at a given speed range, rejecting torque disturbances due to accessory loads, and preventing the engine from stalling. In practical engine operation, unpredictability of the torque, load fluctuations poses serious challenges to control of the stability of the engine operated at idling speed [Balluchi et al, 2002].

In order to obtain some prior knowledge of the engine performance, use has been made of a mathematical model of an engine expressed in form of a transfer function having the form presented in equation 2 [Mhilu, 1995]

$G_{2}(s)=\frac{N_{e}(s)}{Y(s)}=\frac{1}{s+a}$

where, $N_{e}(s)$ is the angular speed (rpm); $Y(s)$ is the fuel rack displacement and the engine design constant $a=28.0$ which is a constant dependent on the engine design parameters used [Hartley, 1977 and Susheel et al, 2002]. In this study the engine design specifications used are: Engine type E108 HATZ DIESEL, 4
Strokes, 4 Cylinders, bore diameter $108 \mathrm{~mm}$, Piston stroke is $110 \mathrm{~mm}$, Cylinder capacity $1007 \mathrm{~cm}^{3}$, and Compression ratio 1:17.

\section{Tachometer}

In order to measure engine speed variations an electronic tachometer coupled to the enginespeed governor feedback loop is used. The dynamic response characteristics of the tachometer is therefore investigated using a first order differential equation representing the transfer function of the form [Schwarzenbach and Gill, 1984]

$G_{3}(s)=\frac{C(s)}{N_{e}(s)}=\frac{1}{1+\tau s}$

In this study $\tau=0.5$ is the time constant dependent to the system parameters, and $C(s)$ is the measured engine speed (rpm) [Checkline, 2004].

An evaluation of system parameter values was carried out and the resulting overall block diagram representing the system's dynamic characteristics for the speed governor, engine and the tachometer evolved as presented in Fig. 2.

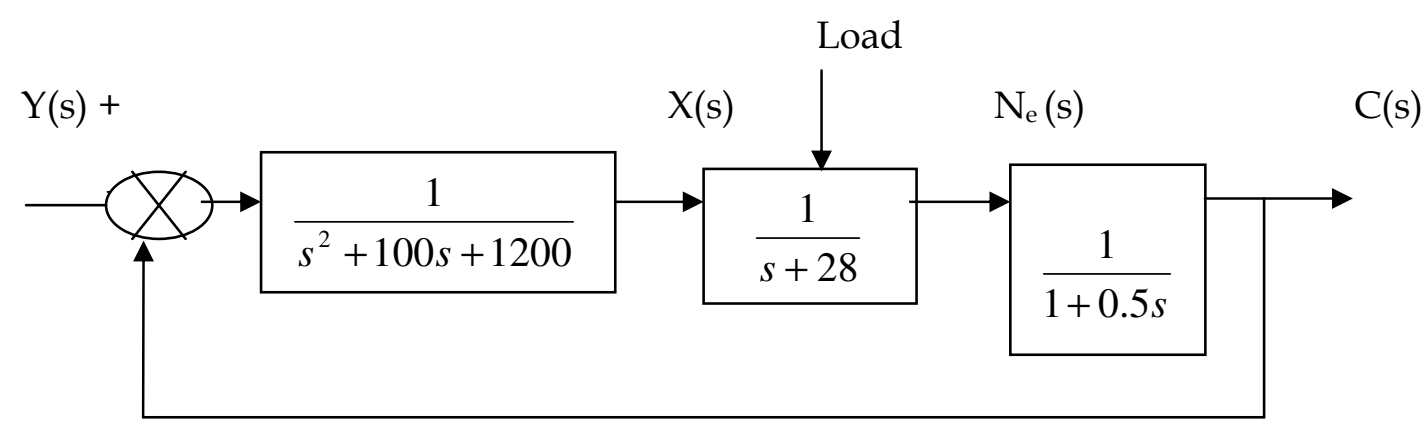

Fig: 2 Block diagram of engine and speed governor model

The corresponding closed loop transfer function of the system was determined and is presented by equation 4

$$
G(s)=\frac{C(s)}{Y(s)}=\frac{1}{0.5 s^{4}+65 s^{3}+2128 s^{2}+20800 s+33600}
$$

where, $\mathrm{C}(\mathrm{s})$ is the engine speed (rpm); $\mathrm{Y}(\mathrm{s})$ is the fuel rack displacement representing the amount of applied force. 
SIMULATION OF THE ENGINE- Investigation of the engine performance has GOVERNOR SYSTEM been made by using digital computer simulation technique. By taking an inverse Analysis of engine-governor system
performance Laplace transform of equation 4 followed by rearrangement the following equation was obtained

$$
\frac{d^{4} c(t)}{d t^{4}}+130 \frac{d^{3} c(t)}{d t^{3}}+4256 \frac{d^{2} c(t)}{d t^{2}}+41600 \frac{d c(t)}{d t}+67200=2 y(t)
$$

The solution of equation 5 is obtained by using the fourth order Runge-Kutta numerical integration algorithm, to obtain the engine speed response to the fuel rack displacements.

Computation work was carried out using a computer program written in C code [Mhilu, 1995 and Molluzo, 1999] by changing the values of fuel rack displacement, y [mm], with a step size, $h=0.0001$ selected for the displacement values ranging from $y \quad(t)=1.0 \mathrm{~mm}$ to $12.0 \mathrm{~mm}$. The step size has been selected to allow for a reasonable plot presentation to be obtained. Simulation results obtained showing the corresponding engine performance (speed) values $\mathrm{Ne}(\mathrm{rpm})$ are shown in Figure 3.

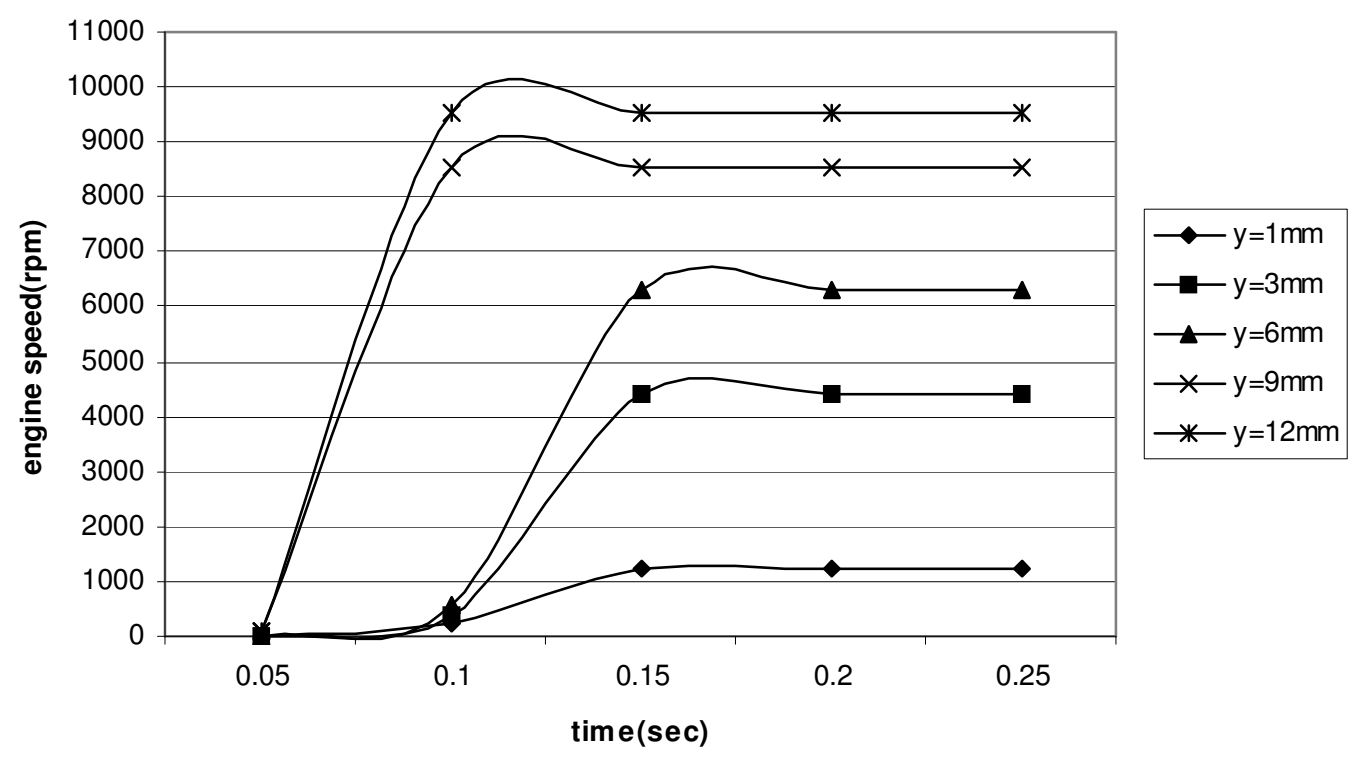

Figure: 3 Engine performance plot for fuel rack displacement between $y=1.0 \mathrm{~mm}$ to $12 \mathrm{~mm}$.

From Fig. 3 it can be seen that with governor fitted to the engine, when the fuel rack is displaced by $\mathrm{y}=1 \mathrm{~mm}$, the engine speed increases slowly at the beginning and then settles to a speed value of about $1200 \mathrm{rpm}$. The rise time for this case starts from $t=0.05$ and proceeds up to 0.1 seconds. Similar results are observed when the fuel rack displacement of $\mathrm{y}=3 \mathrm{~mm}$ is used although in this case the speed settles at $4500 \mathrm{rpm}$. This is because the fuel supplied is more than that supplied when fuel rack displacement was $1 \mathrm{~mm}$. The same behavior is observed for fuel rack displacements of $6 \mathrm{~mm}, 9 \mathrm{~mm}$, and $12 \mathrm{~mm}$ although in this case the speed settles to the final values much faster.

\section{Evaluation of engine-governor system performance at low speeds}

Based on the results presented above, an investigation on the behaviour of the engine performance operated at low speeds was made by adjusting fuel rack displacement values starting from $y=0.4 \mathrm{~mm}, 0.6 \mathrm{~mm}, 0.8 \mathrm{~mm}$ and 
$1.0 \mathrm{~mm}$ to simulate typical engine idling speed conditions.

During the analysis when the fuel rack displacement was set at $y=0.4 \mathrm{~mm}$, the engine was set to run at an idling speed of 600rpm, and when the fuel rack was adjusted at $0.6 \mathrm{~mm}$,
$0.8 \mathrm{~mm}$ and $1.0 \mathrm{~mm}$ the engine speed was observed to increase to $800 \mathrm{rpm}, 1000 \mathrm{rpm}$ and to $1200 \mathrm{rpm}$ respectively. These results are shown in Fig. 4. It can be seen from these results that the engine performance achieve steady state values at different fuel rack displacement values.

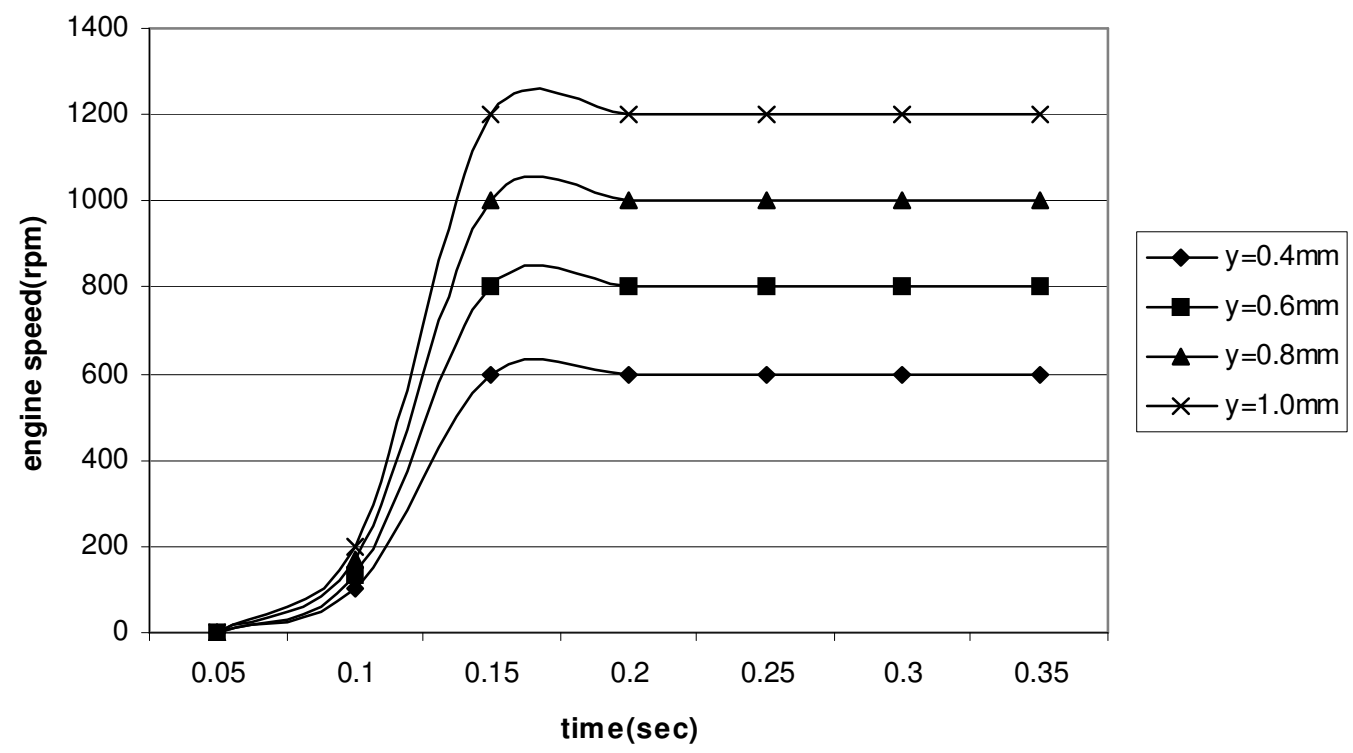

Figure: 4 Engine speed response to fuel rack displacement

\section{Verification of engine-governor system stability at low speeds}

In order to study the behavior of the enginegovernor system operated at low speeds some disturbances were introduced to simulate engine running conditions with fuel control miss match while adjusting the fuel rack displacement at $0.4 \mathrm{~mm}, 0.6 \mathrm{~mm}, 0.8 \mathrm{~mm}$ and
$1.0 \mathrm{~mm}$. The type of disturbance used is based on the application of a unit step forcing function whose transfer function is $G_{d}=\frac{1}{s}$. By introduction of a forcing function into the system, then the resulting open loop transfer function of the system is given by equation 6

$$
G(s) H(s)=G(s) * \frac{1}{s}=\left(\frac{K}{0.5 s^{4}+65 s^{3}+2128 s^{2}+20800 s^{1}+33,600}\right) * \frac{1}{s}
$$

where $\mathrm{H}(\mathrm{s})=1$ as it is a unit feedback system, and $\mathrm{K}$ is a gain value. The closed loop transfer function obtained is presented in equation 7 [Schwarzenbach and Gill, 1984]

$$
G_{4}(s)=\left(\frac{K}{0.5 s^{5}+65 s^{4}+2128 s^{3}+20800 s^{2}+33,600 s+K}\right)
$$

By inspection of equation (7) it is clearly seen that the resulting characteristic equation for the system assumes the form presented in equation 8 


$$
0.5 s^{5}+65 s^{4}+2128 s^{3}+20800 s^{2}+33600 s+K=0
$$

By using equation (8) followed by a subsequent Laplace inversion, the engine performance response under the influence of a disturbance signal was investigated while the fuel rack displacements are kept constant. The investigation was conducted by changing the value of the coefficient $\mathrm{K}$ from $0,0.5,1.0,2.0$ and 10 to simulate different disturbance intensities [Tamura et al, 1990].

The results obtained from this investigation are shown in Figure 5, 6, 7 and 8. These results show that for the engine operation with the coefficient $\mathrm{K}$ set between 0.5 to 2.0 the response behaviour of the engine was satisfactory, and the steady state values are reached after 0.2 seconds.

These results were obtained at the fuel rack displacement of $0.4 \mathrm{~mm}$ as seen from Fig. 5., and they are well comparable with the system response without disturbance at $\mathrm{K}=0$ presented in Fig. 4. When disturbance intensity was increased to $K=10$, the system becomes oscillatory. However this response is quickly reduced to a steady state value after 0.4 seconds.

A similar response was observed when the disturbance intensities were varied from $\mathrm{K}=$ 0.5 to $K=10$ when the fuel rack displacements were set at $\mathrm{y}=0.6,0.8$ and $1.0 \mathrm{~mm}$, as can be seen from Figure 6 through Figure 8 respectively. It has been observed in these figures that as the $\mathrm{K}$ value is increased, the characteristic curve shows an amplified disturbance. This trend remains the same for different $y$ values and at corresponding engine speeds values.

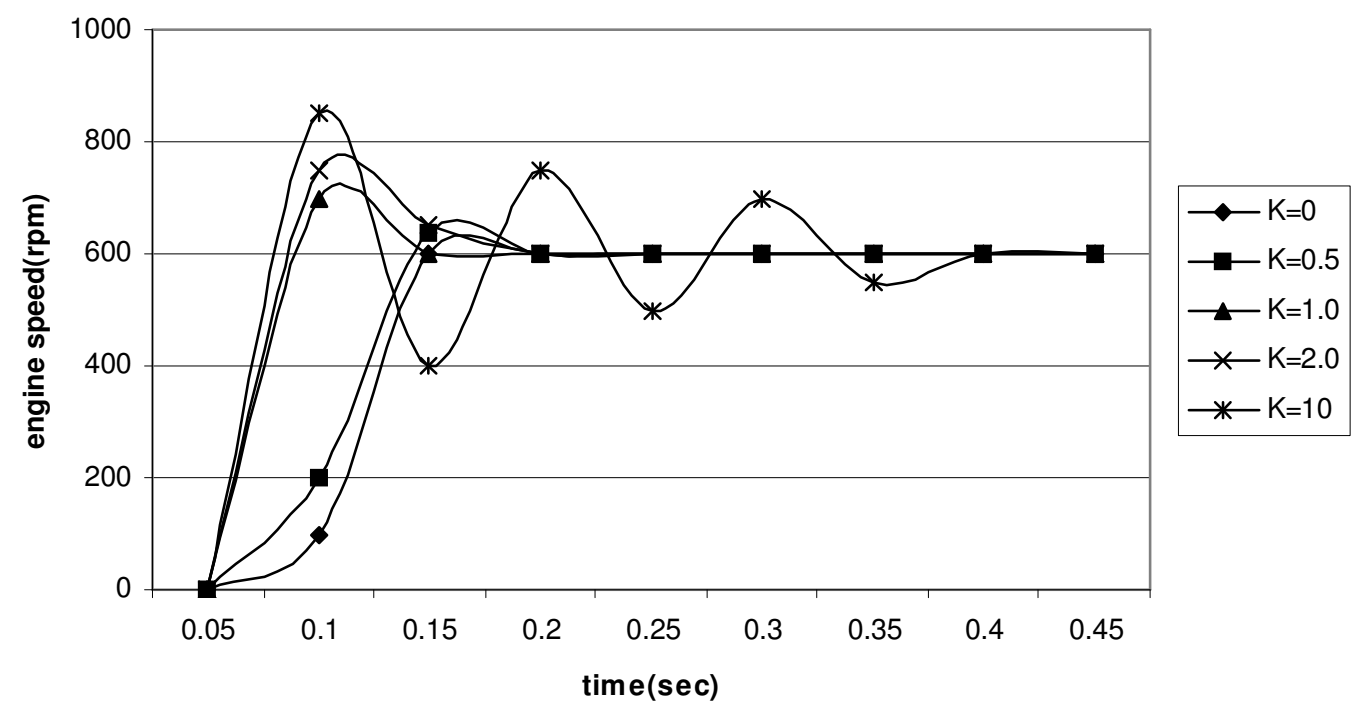

Figure: 5 Influence of disturbance intensities on engine performance at $\mathrm{y}=0.4 \mathrm{~mm}$ (Engine speed $\mathrm{Ne}=600 \mathrm{rpm})$ 


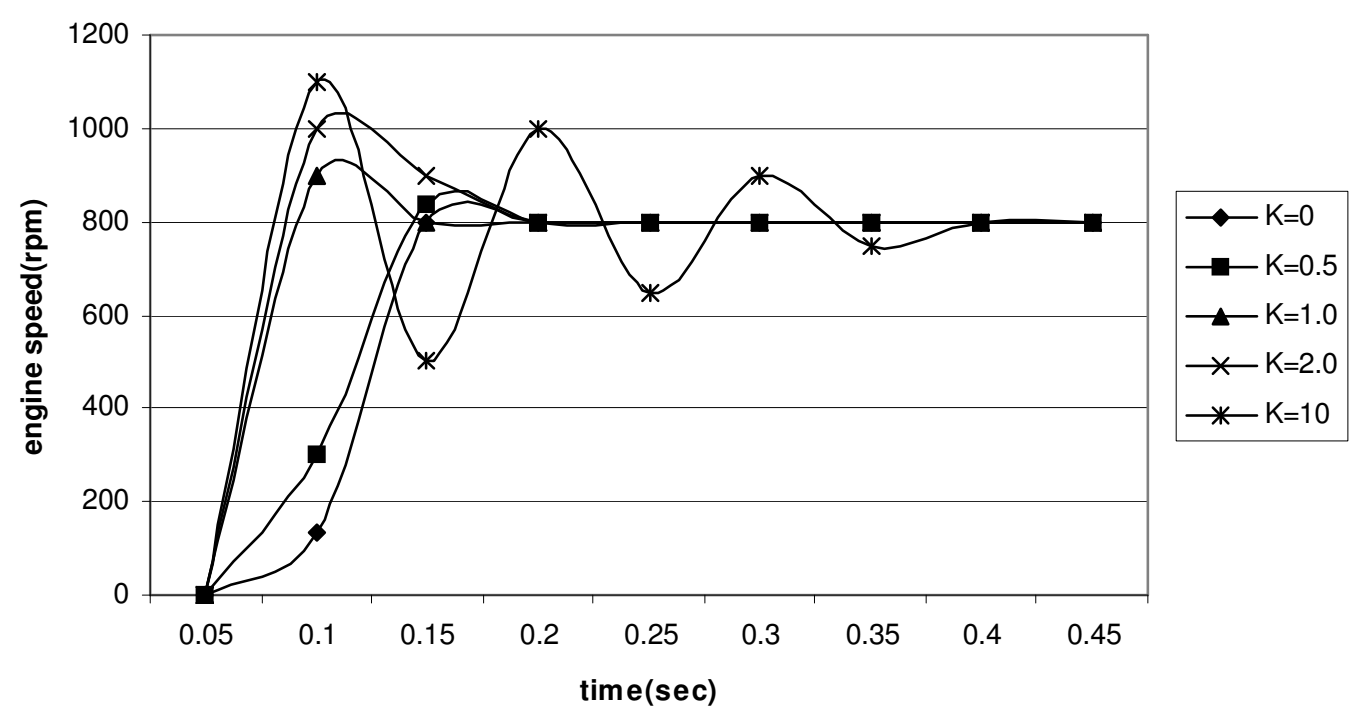

Figure: 6 Influence of disturbance intensities on engine performance at $\mathrm{y}=0.6 \mathrm{~mm}($ Engine speed $\mathrm{Ne}=800 \mathrm{rpm})$

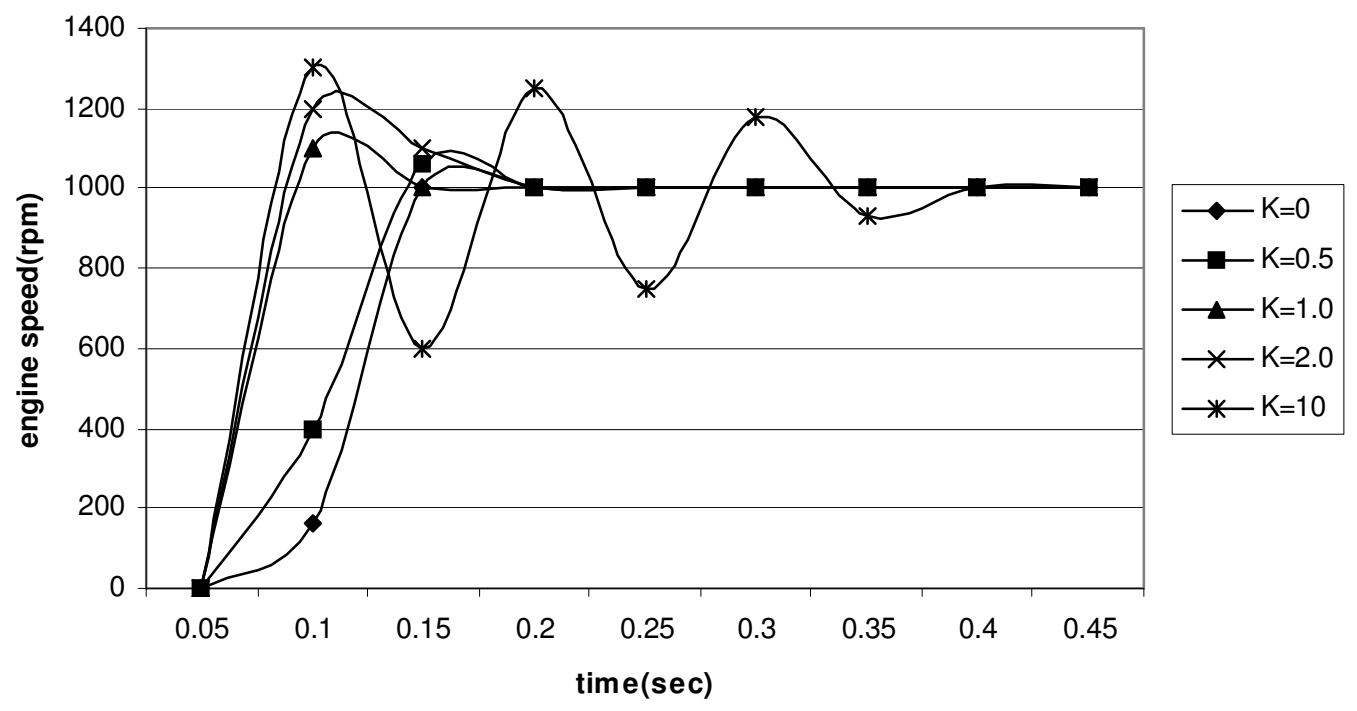

Figure: 7 Influence of disturbance intensities on engine performance at $\mathrm{y}=0.8 \mathrm{~mm}$ (Engine speed $\mathrm{Ne}=1000 \mathrm{rpm})$ 


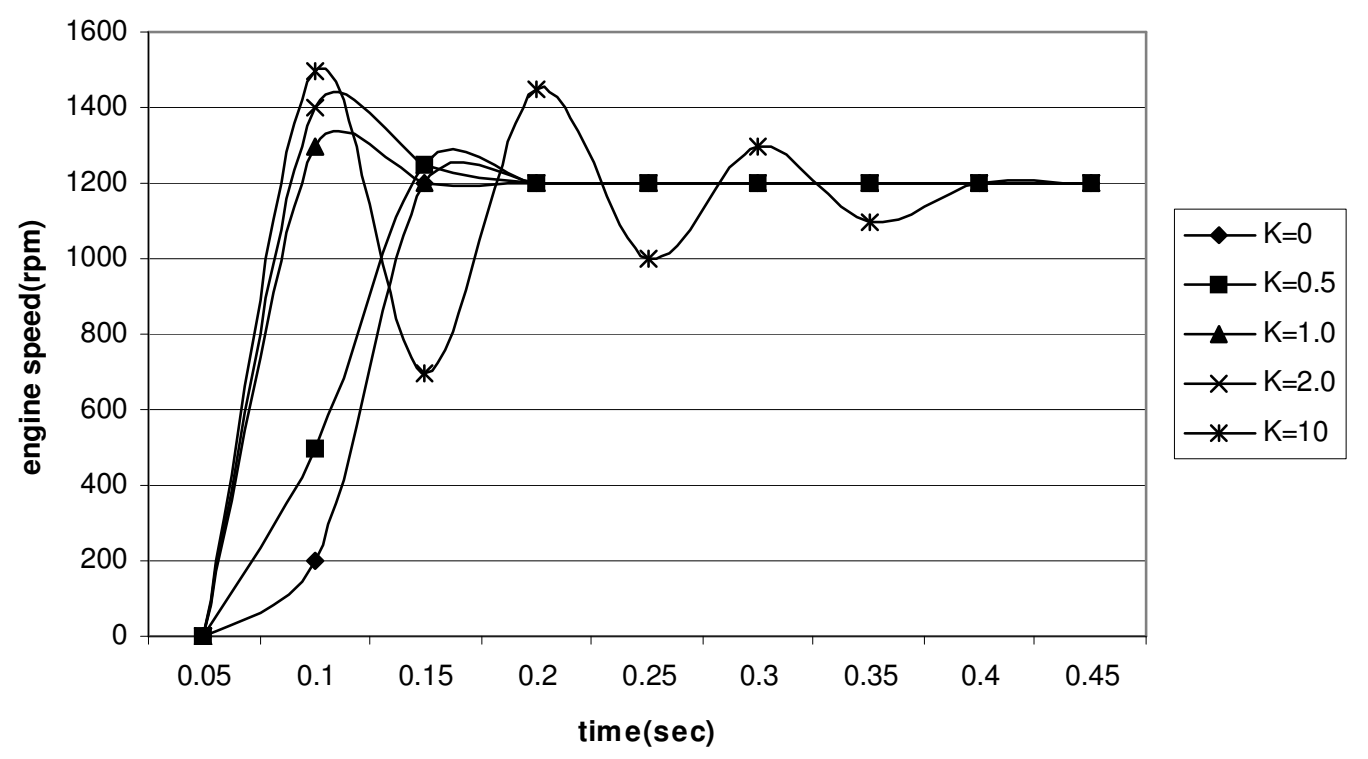

Figure: 8 Influence of disturbance intensities on engine performance at $\mathrm{y}=1.0 \mathrm{~mm}$ (Engine speed $\mathrm{Ne}=1200 \mathrm{rpm}$ )

\section{DISCUSSION OF RESULTS}

In this study, the influence of speed governor characteristics on the stability of engine operated at low speeds is elucidated. The research was designed in order to optimize engine and governor parameters for best engine operation at low speed conditions. Such simulations are essential as they establish the best design parameters for better performance.

In order to investigate the influence of the speed governor on the stability of the engine operated at low speeds, studies carried out took into account the engine performance for the fuel rack displacement values of $y=0.4,0.6$, 0.8 and $1.0 \mathrm{~mm}$ respectively of which the engine performance could be maintained at low speeds. The engine performance was investigated at these fuel rack displacement values to simulate various engine loading conditions, corresponding to engine speed values of 600, 800, 1000 and 1200rpm respectively (see Fig.4). The results show a tendency of fast speed increase with a rise time increases of 0.15 seconds before reaching steady state value.

Further investigation was made by subjecting the engine to a disturbance by introduction of a step forcing function of magnitude of $K=0.5$,
1.0, 2.0 and 10 to emulate varying disturbance intensities while maintaining fuel rack displacement values at $\mathrm{y}=0.4,0.6,0.8$ and $1.0 \mathrm{~mm}$. The results presented in Fig. 5 through Fig. 8 show that, the transient response of the engine- governor system for varying disturbance values of $\mathrm{K}=0.5$ to 2.0 give satisfactory and steady state values achieved after 0.2 seconds. These results are well comparable to the engine- governor system response presented in Fig. 4 where no disturbance was introduced. When disturbance intensity was increased to $K=10$, the system showed a tendency of becoming oscillatory which indicates an engine performance limit before instability occurs. However this response quickly reduces to a steady state value after 0.4 seconds due to the corrective action contributed by the governor.

These results provide an important information with regard to improved features of speed governor designs in the future, that would ensure for good engine operation and hence long service life of the engine. The obtained results can therefore be used as a bench mark for proper engine tuning and help to reduce the problem of engine stalling or racing which affects the engine stability. By achieving stable operation of the engine a reduction on the fuel 
consumption and emission of pollutants from the engine can also be achieved.

\section{CONCLUSION}

In this paper an investigation of the enginegovernor system stability operated at low speeds has been conducted. When the engine was subjected to some parameter changes by varying fuel rack displacement values it is evidenced that with low fuel rack displacement values good engine-governor system operation stability was achieved.

In order to verify the robustness of the enginegovernor system used further stability analysis of the system was made by introducing some external disturbances. The results obtained show that at low disturbance intensities no significant influence was observed on the engine performance, but at higher values some significant change in performance was observed. With the disturbance intensity increased to higher values the system was observed to be oscillatory which would indicate an engine performance limit before instability occurs.

The solution for system equations was obtained using digital computer simulation in which a fourth order Runge-Kutta numerical integration method was employed while system equations were written in C code computer programs.

\section{REFERENCES}

Balluchi, A., Benvenuti, L., Berardi, L., De Santi, E., Di Benedelto, M.D., Girasole, G. and Pola, G., ( 2002). Engine Idle Speed Control via Maximal Ssafe Set Computation in the Crank Angle Domain, Dipartimento di Ingegneria Elettrica, Universita' de L' Aquila, Monteluco di Roio, 67040 L'Aquila, Italy.

Bosch, R., (1986). Automotive Hand Book, 2nd Edition, Automotive Equipment Product Group, Department of Technical Information (KH/VDT), Postfach 50, D7000 , Stutgart.
Chan, S.H., (1997.). Effects of Engine Operating Conditions on Thermodynamic Cycle, JSME International Journal, Vol. 40, Series B, No. 1, 175-182.

Checkline, (2004). Digital Tachometer Combination Contact and No-Contact, CD-2000 Portable, Precision Instruments for Quality Control, Electromatic Equipment CO., Publication, 600 Oakland Ave Cedarhurst, NY 11516, USA.

Choi, W.C., (1998). Effects of Operating Speed on 3D Mean Flows Measured at the End of Intake Stroke in an IC Engine, JSME International Journal, Vol.41, Series B, No.2, 338-343.

Hartley, J., (1977). “Engine design series: fuel systems- diesel "Automotive Engineer Journal, Incorporating the Journal of Automotive Engineering and Automotive design Engineering, ISSN 0307-6490, Vol 2 No 6.

Heisler, H., (1985). "Vehicle and engine Technology Volume 1" Edward Arnold (Publishers) Ltd, 41 Bedford square, London WC1 B 3 DQ.

Hillier, V.A.W., and Pittuck, F., (1972). "Fundamentals of Motor vehicle Technology" 2nd Ed. Hutchison \& co (publishers) Ltd, 3 Fitzroy square, London W, 140-141.

Khovakh, M., Stepanov, Y., Arkhangelsk., V., Trusov, V., Vikhert, M. and Voinov, A., (1979). "Motor Vehicle Engines" Mir Publishers, Moscow.

Mhilu, C.F., (1995). Parameter Optimization Procedure for the Design of Electrohydraulic Servomechanisms, Uhandisi Journal, Vol.19, No.2, 153-163.

Molluzo, J.C., (1999). "C++ for business programming “ Prentice-Hall, Inc, USA.

Santillan, M., Maya, G., and Angulo-Brown, F., (2001). Local Stability Analysis of an Endoreversible Curzon - Ahborn - 
Narkov Engine Working in a Maximum Power Like Regime, J. Phys. D: Applied Physics, Vol.34, 2068-2072.

Shoji, T., (1997). Effect of Cycle -to-Cycle Variations in Spray Characteristics on HC Emission in D1 Diesel Engines, JSME International Journal, Vol.40, Series B, No.2, 312-319.

Schwarzenback, J., and Gill, K.F., (1984). "System modeling and control", Second Edition, Edward Anorld, London.

Susheel, G.K., Yogesh, K.H., and Kamalakar, P.K., (2002). Control System Design for Speed Control of Turbocharged Diesel
Engine, Department of Mechanical Engineering, Sardar Patel College of Engineering, University of Mumbai, India.

Tamura, N, Kishimoto, I., Maeda, T., and Sato, I., (1990). "Development of optimization System of control Parameters for Electronic Digital Governor", Bulletin of the M.E.S.J., Vol 18, No.1, Japan.

Yamaguchi, J., (1984). "Heavy diesel is electronically managed "Automotive Engineering Journal, Annual Congress Issue. 